\title{
Effect of methamphetamine dependence on inhibitory deficits in a novel human open-field paradigm
}

\author{
Brook L. Henry • Arpi Minassian • \\ Mandy van Rhenen $\cdot$ Jared W. Young $\cdot$ \\ Mark A. Geyer • William Perry • \\ Translational Methamphetamine AIDS Research Center \\ (TMARC) Group
}

Received: 9 September 2010 / Accepted: 4 January 2011 /Published online: 29 January 2011

(C) The Author(s) 2011. This article is published with open access at Springerlink.com

\begin{abstract}
Rationale Methamphetamine (MA) is an addictive psychostimulant associated with neurocognitive impairment, including inhibitory deficits characterized by a reduced ability to control responses to stimuli. While various domains of inhibition such as exaggerated novelty seeking and perseveration have been assessed in rodents by quantifying activity in open-field tests, similar models have not been utilized in human substance abusers. We recently developed a cross-species translational human open-field paradigm, the human behavior pattern monitor (hBPM), consisting of an unfamiliar room containing novel and engaging objects. Previous work demonstrated that manic bipolar subjects exhibit a disinhibited pattern of behavior in the hBPM characterized by increased object interactions. Objectives In the current study, we examined the effect of MA dependence on inhibitory deficits using this paradigm. hBPM activity and object interactions were quantified in 16 abstinent MA-dependent individuals and 18 matched drug-
\end{abstract}

B. L. Henry · A. Minassian · J. W. Young $\cdot$ M. A. Geyer $\cdot$

W. Perry

Department of Psychiatry, University of California San Diego,

La Jolla, CA, USA

M. A. Geyer

VA San Diego Healthcare System,

San Diego, CA, USA

M. van Rhenen

University of Utrecht,

Utrecht, Netherlands

B. L. Henry $(\bowtie)$

UCSD Department of Psychiatry,

140 Arbor Drive, Mailcode 0851,

San Diego, CA 92103-0851, USA

e-mail: blhenry@ucsd.edu free comparison subjects. The Wisconsin card sorting task (WCST) and the positive and negative syndrome scale (PANSS) were administered to assess executive function and psychopathology.

Results MA-dependent participants exhibited a significant increase in total object interactions, time spent with objects, and perseverative object interactions relative to comparison subjects. Greater object interaction was associated with impaired performance on the WCST, higher PANSS scores, and more frequent MA use in the past year.

Conclusions Abstinent MA-dependent individuals exhibited impaired inhibition in the hBPM, displaying increased interaction with novel stimuli. Utilization of this measure may enable assessment of inhibitory deficits relevant to drug-seeking behavior and facilitate development of intervention methods to reduce high-risk conduct in this population.

Keywords Methamphetamine - Inhibition · Human behavior pattern monitor - Exploration - Prefrontal cortex . Cognitive deficits

\section{Introduction}

Methamphetamine (MA) is a potent and addictive drug used with increasing prevalence worldwide (Romanelli and Smith 2006). Escalating use in the United States has been described as an epidemic (Barr et al. 2006), with 1.3 million individuals reporting use over the past year (Substance Abuse and Mental Health Services Administration 2009). From 2007 to 2009, MA seizures from domestic laboratories and the Southwest border have increased significantly, indicating rising production of the drug in both the U.S. and Mexico (U.S. Department of Justice National Drug Intelli- 
gence Center 2010). These statistics are of particular concern, given strong evidence linking MA exposure to adverse medical, cognitive, and psychosocial consequences (Scott et al. 2007).

Chronic MA administration has been associated with cognitive dysfunction in a variety of domains, including deficits in executive function and response inhibition (Kalechstein et al. 2003; Rippeth et al. 2004; Simon et al. 2000; Simon et al. 2002). Inhibitory deficits, or the inability to withhold or control an action or thought, have a critical impact on drug-seeking behavior, aggression, and risky sexual activities associated with MA use (Jentsch and Taylor 1999; Semple et al. 2010; Watanabe-Galloway et al. 2009). Impaired inhibition in MA-dependent individuals has typically been demonstrated using standard neuropsychological tests, including variants of the Stroop color-word task (Salo et al. 2002; Salo et al. 2009b; Simon et al. 2000), the stop-signal task (Monterosso et al. 2005), and the Wisconsin card sorting task (WCST) (Woods et al. 2005). Recent evidence also indicates a direct association between MA-induced cognitive dysfunction and neurotoxicity in prefrontal cortex (PFC), a region that plays a vital role in decision making and inhibitory control (Sakagami et al. 2006). For example, impaired WCST performance in MAdependent participants was correlated with lower frontal gray matter density (Kim et al. 2006), hypometabolism, and reduced fractional anisotropy in frontal white matter (Chung et al. 2007; Kim et al. 2005).

In contrast to the neuropsychological tests administered to humans, the effects of drugs of abuse in rodents are often assessed using open-field paradigms that enable quantification of exploration (Ellison and Eison 1983; Geyer et al. 1986). Deficits in inhibitory behavior manifest in several domains relevant to the concept of exploration, including increased novelty seeking, i.e., an increase in exploration of novel stimuli and perseveration, i.e., an inability to inhibit prepotent or ongoing responses resulting in a decline in behavioral variety (Goodwin and Jamison 1990). Inhibitory deficits may be evaluated using "object-oriented" paradigms such as the holeboard task (where rodents can investigate objects placed inside holes situated around an enclosure) (File and Wardill 1975) or the object retrieval/detour task (where primates are required to inhibit the tendency to reach directly towards a reinforcing object placed behind a transparent barrier) (Jentsch and Taylor 1999). The importance of frontal function on inhibitory behavior as assessed by response to novel objects has been demonstrated in multiple species. Ablative or excitotoxic lesions of the frontal cortex in marmoset and rhesus monkeys have been shown to impair inhibitory control on the object retrieval/detour task (Diamond and Goldman-Rakic 1985; Dias et al. 1996). Similarly, patients with frontal lobe lesions also demon- strate uncontrolled grasping behavior when objects are placed within reach (Lhermitte 1983).

While rodent behavioral assays such as the open-field test have been used to model human drug abuse and psychiatric illness for several decades (Geyer et al. 1986), there has been a surprising dearth of any corresponding paradigm in humans. To address this deficit, our group recently designed a novel human open-field paradigm (the human behavior pattern monitor or hBPM), based on the traditional rodent open-field apparatus (Young et al. 2007). In this procedure, subjects are introduced into a room containing several items of furniture and a number of colorful and tactile objects designed to invite exploration (Perry et al. 2009). We have used the hBPM previously to describe the exploratory behavior of acutely hospitalized psychiatric patients diagnosed with bipolar disorder (BD) or schizophrenia (Perry et al. 2009). Our findings indicate that BD patients in a manic state exhibit a disinhibited pattern of behavior characterized by increased interaction with novel objects, more interactions with multiple objects at one time, greater object perseveration, and a tendency to approach objects more frequently compared to healthy comparison participants (Perry et al. 2010). BD patients also demonstrated a unique pattern of disregard for social norms, including wearing objects (such as masks or eyeglasses placed in the room) and opening potentially private cabinet drawers (Perry et al. 2010).

The objective of the current study was to assess inhibition in the hBPM in abstinent MA-dependent individuals and a drug-free comparison group. Given that MA exposure is characterized by impaired inhibition linked to prefrontal dysfunction, similar to BD (Leibenluft et al. 2007; Salo et al. 2009b), we hypothesized that MAdependent participants would exhibit a pattern of increased object interaction indicative of inhibitory deficits relative to drug-free comparison subjects. Based on prior studies linking WCST performance to prefrontal cortex abnormalities (Chung et al. 2007), we also administered the WCST to evaluate the relationship between neuropsychological deficits on this task and exploration in the hBPM.

\section{Materials and methods}

\section{Participants}

Sixteen participants with a history of MA dependence were recruited in collaboration with the HIV Neurobehavioral Research Center (HNRC), an institute that works closely with community organizations and drug treatment centers in the San Diego area. Subjects met SCID (Structured Clinical Interview for Diagnostic and Statistical Manual-IV (DSM-IV) criteria (First et al. 1994) 
for lifetime MA dependence, as well as DSM-IV criteria for MA abuse or dependence within the past 2 years. Subjects were also required to be abstinent from the drug for at least 7 days before testing. Drug use history, including the length of use and estimated quantity of MA exposure were obtained through a substance use questionnaire (Henry et al. 2010) (Table 1). Eighteen drugfree comparison subjects who had never met the SCID criteria for any substance use disorder were recruited from advertisements in the San Diego community. Comparison and MA groups were comparable for age, gender, education, ethnicity, and had equivalent premorbid IQ as assessed by the Peabody picture vocabulary test (Dunn and Dunn 1997) (Table 1). All participants provided written informed consent to the current protocol approved by the UCSD institutional review board.

Participants from both groups were excluded if they met any of the following conditions: (1) SCID criteria for schizophrenia, bipolar disorder, or current major depression; (2) any neurological conditions or head trauma; (3) treatment with electroconvulsive therapy; (4) infection with HIV or hepatitis C; (4) a positive result for cocaine, amphetamine, PCP, opiates, or cannabis on a urine toxicology Rapid Drug Screen (Pharmatic Inc., San Diego, CA) administered during the test session; (6) substance dependence on illegal drugs other than MA in the past 5 years; (7) alcohol abuse or dependence within the past 12 months; and (8) a remote (i.e., more than 5 years prior to study enrollment) but significant history of alcohol or other substance dependence, as described in previous studies (Rippeth et al. 2004; Woods et al. 2005).
Human behavior pattern monitor

The hBPM, which has been described elsewhere (Perry et al. 2009; Young et al. 2007), consists of a 3.5 $\times 4.9-\mathrm{m}$ rectangular room furnished with a desk, two bookcases, a short filing cabinet, a corkboard mounted on the wall, several tall filing cabinets, and a rear window covered by horizontal blinds. The room does not contain any chairs in order to promote participant activity. Eleven engaging toys designed to invite contact and stimulate exploration were placed around the room. These objects were selected to meet several criteria, including being safe, colorful, tactile, and manipulable (Pierce and Courchesne 2001). Ten items were placed in visible locations around the room (on the desk, filing cabinet, bookcase shelves, and one hung from the corkboard) while one item (a harmonica) was concealed in the top drawer of the short filing cabinet. The group of toys included a feather mask which could be worn, a soft baseball, a kaleidoscope, finger puppets, a paddle ball game, and a doll. Activity in the hBPM was recorded by a hidden ceiling camera equipped with a fish-eye lens capable of viewing the entire room. Video images were stored in digital format on a computer in an adjacent room and recorded at a frequency of 30 frames per second (Perry et al. 2010).

Before entering the hBPM, each participant was fitted with a LifeShirt vest (Vivometrics 2002), an ambulatory monitoring system that records acceleration and cardiac data on a personal digital assistant (PDA) housed inside a fanny pack worn around the waist (Henry et al. 2009; Minassian et al. 2009). Participants were directed to wait in
Table 1 Demographic factors and drug use history for comparison (comp, $n=16$ ) and MAdependent (MA, $n=18$ ) subjects

Peabody picture vocabulary test results are presented as ageadjusted standard scores. The PANSS total score can range from 30 to 210 , and the positive and negative symptoms subscales range from 7 to 49 . Higher scores indicate more severe psychopathology. Data are represented as means \pm S.E.M.

METH methamphetamine, ns not significant

${ }^{*} p<0.001 ; * * p<0.01$, significant group differences

\begin{tabular}{lccc}
\hline Parameter & Comparison & MA dependent & Difference \\
\hline Age (years) & $36.1 \pm 2.5$ & $36.7 \pm 2.1$ & $\mathrm{~ns}$ \\
Gender & $12, \mathrm{M} ; 4, \mathrm{~F}$ & $15, \mathrm{M} ; 3, \mathrm{~F}$ & $\mathrm{~ns}$ \\
Education (years) & $13.9 \pm 0.6$ & $13.6 \pm 0.5$ & $\mathrm{~ns}$ \\
Ethnicity ( $n$ ) & & & $\mathrm{ns}$ \\
Caucasian & 12 & 13 & \\
Latino & 2 & 2 & \\
African-American & 2 & $11 / 7$ & $\mathrm{~ns}$ \\
Smokers/non-smokers & $6 / 10$ & $95.8 \pm 2.2$ & $\mathrm{~ns}$ \\
Peabody picture vocabulary test scores & $102.5 \pm 3.6$ & $23.5 \pm 2.1$ & \\
Age at first METH use (years) & - & $10.3 \pm 1.6$ & \\
Duration of continuous METH use (years) & - & $22.4 \pm 2.4$ & \\
Frequency of METH use (per month) & - & $4410 \pm 678$ & \\
Total amount of METH used (in grams) & - & $52.1 \pm 20.9$ & \\
Number of days METH used in past year & - & $290.6 \pm 52.4$ & \\
Duration of METH abstinence (days) & - & $43.9 \pm 1.5 *$ & MA $>$ comp \\
PANSS total score & $34.9 \pm 1.0$ & $12.4 \pm 0.9 * *$ & MA $>$ comp \\
PANSS positive symptoms & $8.4 \pm 0.4$ & $8.1 \pm 0.6$ & $\mathrm{~ns}$ \\
PANSS negative symptoms & $7.7 \pm 0.3$ & & \\
\hline
\end{tabular}


the hBPM for an indeterminate period while the experimenter prepared another task. They were not provided any other explicit instructions.

\section{Wisconsin card sorting test}

Participants were administered the WCST-64 card version (Heaton 1993). The WCST is a well-established measure of executive function, designed to assess deficits in rule attainment and cognitive set shifting linked to frontal cortex pathology (Goldberg and Miller 1986; Perry and Braff 1998). The WCST requires participants to sort cards based on three perceptual dimensions (color, shape, and number) and provides feedback to allow the subject to identify the correct matching rule. After a specific number of correct responses, the card sorting category changes. Failure to abandon the previous sorting rule when it has been explicitly changed is associated with prefrontal dysfunction and perseverative behavior, a tendency to engage in maladaptive repetitive responses (Perry and Braff 1998). Dependent measures include: (1) total number of errors, (2) perseverative errors, and (3) number of categories completed. Error scores for the task are converted to $T$ scores corrected for age and education, where a higher score indicates better performance on the measure.

\section{Positive and negative syndrome scale}

We administered the PANSS to assess for the presence of psychopathology, given that chronic MA exposure has been associated with increased prevalence of psychotic symptoms (McKetin et al. 2006). The positive and negative syndrome scale (PANSS) consists of a 30-item rating scale designed to assess positive psychotic symptoms that include paranoia and hallucinations, negative symptoms that include flat affect and emotional withdrawal, and miscellaneous symptoms of general psychopathology that include anxiety and poor attention (Opler et al. 2007). Total PANSS scores range from 30 to 210, with higher scores indicating more severe psychopathology, while scores below 60 have been interpreted as "mild illness" and scores below 50 described as "borderline illness" (Leucht et al. 2005).

\section{Data collection}

Video footage of participant activity in the hBPM was manually scored by trained raters blind to the group condition of the subjects. Exploratory behavior during the 15-min session was quantified in 1-s increments and kappa reliability coefficients for rater-coded measures ranged from 0.91 to 0.96 (Perry et al. 2010). To assess object interaction, we quantified: (1) the total number of object interactions (defined as deliberate physical contact with a novel object with any part of the body, e.g., hand or foot); (2) time spent with objects (the number of seconds spent in physical contact with any of the objects during the 15-min session); (3) multiple object interactions (instances when a participant interacts with more than one object at the same time); (4) percent perseverative interactions (number of repeated interactions with the same objects divided by the total number of all object interactions).

In addition to quantifying interaction with the 11 toys placed in the room, we also assessed subject engagement with three other novel stimuli: (1) opening the cabinet drawers, (2) manipulating the blinds covering the rear window, (3) unzipping the fanny pack and examining the LifeShirt PDA. These actions were included as measures of exploration based on the observed prevalence of these behaviors in psychiatric populations relative to healthy comparison participants (Perry et al. 2010; Perry et al. 2009; Young et al. 2007). According to a recent study, individuals with bipolar mania were characterized by a unique tendency to investigate drawers and wear the mask in the hBPM, behaviors hypothesized to demonstrate a failure to observe socially appropriate boundaries (e.g., opening a private drawer or wearing an item that may belong to another individual) (Perry et al. 2010). Thus, these activities were also quantified in the current report.

To assess participant movement in the hBPM, a 64sector grid was generated from $x-y$ coordinate data derived from the digitized videos using proprietary software (TopScan 1.0; Clever Systems Inc., Washington, DC) as previously described (Perry et al. 2009). The average time and entries in 18 object-proximal sectors, defined as sectors that are immediately adjacent to the novel objects in the room, were determined for each group. In addition, total time spent walking in the room was quantified as a measure of overall activity.

\section{Statistical analyses}

Statistical analyses were performed using SPSS. Data were examined for normality of distribution and homogeneity of variance using Levene's test. Initial assessment of the results indicated evidence of skewed and kurtotic score distributions. To maximize normality for each variable, square root transformations were applied to total object interactions, time spent with objects, time in objectproximal sectors, and the amount of MA use in the past year while $\log$ transformations were applied to objectproximal sector entries and time spent walking (Zar 1999). Following these modifications, measures of skew and kurtosis were restricted to a range between -1 and +1 for all variables while the group inequality of variance observed for the total number of object interactions and 
time spent with objects was corrected to produce a null Levene's test for these measures.

Group effects on exploratory behavior during the 15-min hBPM session were analyzed using multivariate analysis of variance (MANOVA) for six variables, including total object interactions, mean time spent with objects, percent perseverative interactions, time spent walking, and average time and entries in object-proximal sectors. Univariate ANOVAs were subsequently conducted for each parameter. Post hoc differences were examined using Bonferroniadjusted multiple $t$ test comparisons, and $r$ was calculated as the effect size (Rosenthal 1991). Given the extremely low prevalence of multiple object interactions in both groups (averaging less than one per person), this measure was assessed separately as a dichotomous variable (present or absent for each participant) and analyzed with the chisquare test. To determine if exploration varied over time, object interaction data were calculated separately for each of the three 5-min epochs within the 15-min hBPM session. Mixed-design ANOVAs were conducted for each variable with group as a between-subjects factor and epoch as a repeated measure.

Bivariate Pearson $r$ correlations were performed to compare relationships between hBPM measures and characteristics of MA use, including the age of first drug use, duration of continuous drug use, the total amount of drug consumed, frequency of use, number of days of MA use in the past year, and length of abstinence from the drug.

WCST and PANSS measures were assessed using independent sample $t$ tests. PANSS data were collected for all subjects; however, two individuals in the drug-free comparison group and one subject in the MA-dependent group did not receive the WCST. Bivariate Pearson $r$ correlations were performed to compare WCST and PANSS scores with activity in the hBPM. To reduce the probability of a type I error associated with a large number of statistical analyses, the level of significance for comparisons was set at $p<0.025$.

\section{Results}

The MANOVA performed for hBPM data indicated a significant main effect of group $[F(7,26)=3.9, p<0.01]$. Subsequent univariate ANOVAs revealed that MAdependent participants exhibited an increase in total object interactions $[F(1,32)=11.8, p<0.01]$, time spent with objects $[F(1,32)=11.0, p<0.01]$, percent perseverative interactions $[F(1,32)=15.9, p<0.001]$, and showed a trend towards elevated object-proximal sector entries $[F(1,32)=$ $3.8, p=0.057$ ] compared to the drug-free comparison group as illustrated in Fig. 1. Significant group differences were characterized by moderate to large effect sizes (Table 2). In

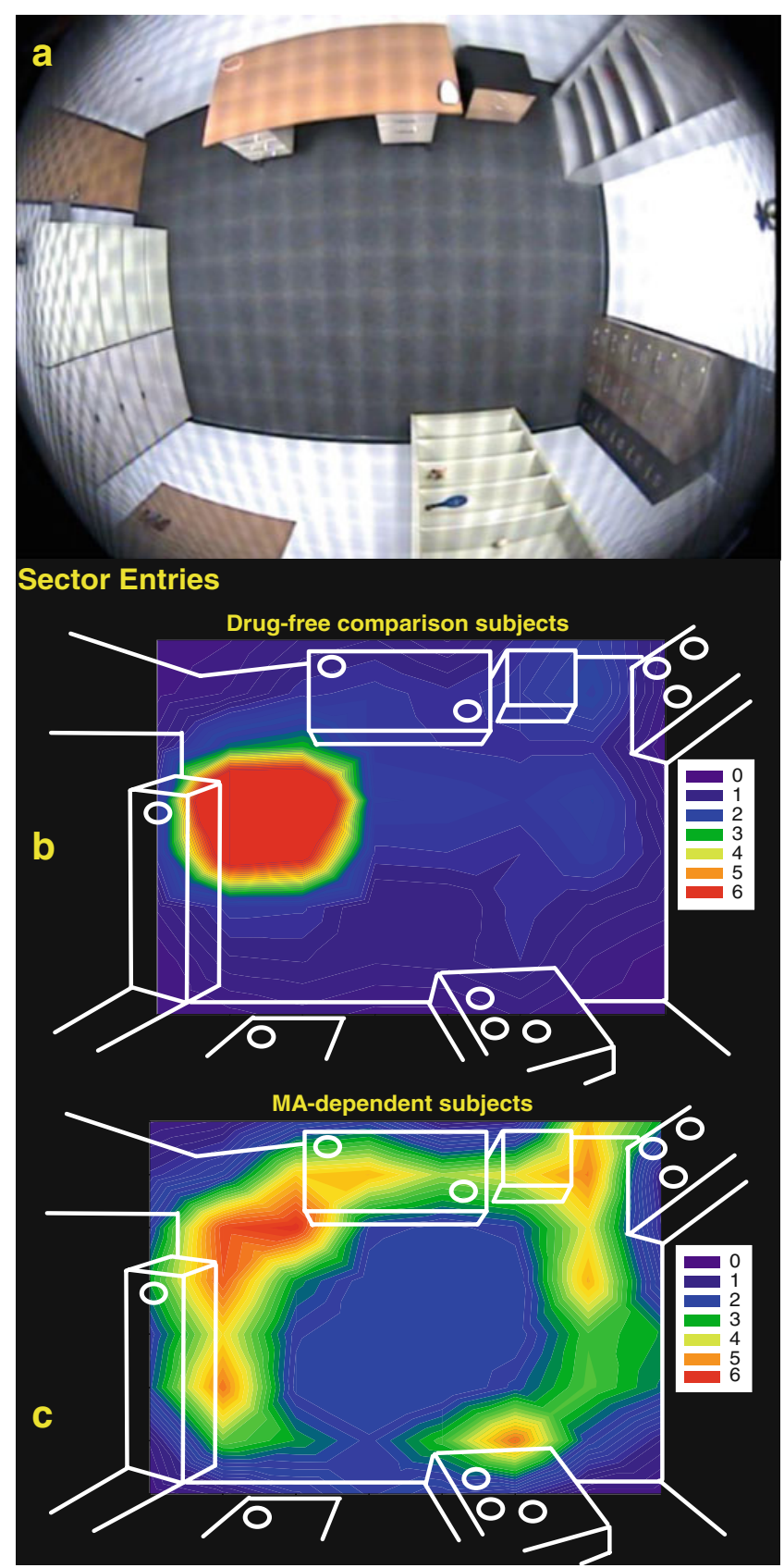

Fig. 1 The distribution of average sector entries across a grid of 64 sectors mapped over the hBPM (a) is illustrated for drug-free comparison (b) and MA-dependent (c) subjects. High intensity activity is denoted by brighter regions, while darker areas indicate low activity. The objects placed around the room are shown as white circles. While drug-free comparison subjects tended to wait near the door in the upper left portion of the hBPM, MA-dependent participants exhibited significantly more object-proximal sector entries throughout the room

contrast, total time spent walking and time in objectproximal sectors did not differ between the groups. In addition, none of the participants in either group wore any of the objects (e.g., putting the mask on their face), while an equal number (two subjects in each group) chose to open the cabinet drawers. However, chi-square analysis indicated 
Table 2 hBPM measures for drug-free comparison $(n=16)$ and MA-dependent $(n=18)$ subjects during the 15-min session

\begin{tabular}{|c|c|c|c|}
\hline hBPM measure & Comparison & METH dependent & Effect size \\
\hline Total number of object interactions & $2.1 \pm 0.8$ & $8.8 \pm 2.0^{*}$ & 0.52 \\
\hline Mean time spent with objects (seconds) & $55.0 \pm 26.8$ & $215.3 \pm 47.2 *$ & 0.51 \\
\hline Percent of participants engaging in multiple object interactions & $0 \%$ & $28 \% * *$ & 0.39 \\
\hline Percent object perseveration & $3.1 \pm 2.1$ & $27.1 \pm 5.3 * * *$ & 0.58 \\
\hline Time in object proximal sectors (seconds) & $207.8 \pm 68.3$ & $227.4 \pm 58.7$ & 0.11 \\
\hline Entries in object proximal sectors & $11.4 \pm 3.9$ & $36.7 \pm 14.6^{\mathrm{a}}$ & 0.34 \\
\hline Time spent walking (seconds) & $87 \pm 36$ & $100 \pm 46.1$ & 0.07 \\
\hline
\end{tabular}

Data are represented as means \pm S.E.M. Effect sizes are shown as $r$ values, with the exception of the multiple object interaction data, where the effect size of the chi-square analysis was estimated with Cramer's V

METH methamphetamine

${ }^{*} p<0.01 ; * * p<0.05 ; * * * p<0.001$, significant group differences

${ }^{\mathrm{a}}$ Indicates a trend $(p<0.1)$

that a significantly higher percentage of MA-dependent participants engaged in multiple object interactions relative to comparison $\left(X^{2}=5.2, p<0.05\right)$.

Analysis of exploratory behavior over the course of the 15-min session did not indicate any significant group by epoch interaction. However, there was a main effect of epoch on total object interactions $[F(1,31)=5.8, p<0.01]$ and walking $[F(1,31)=5.3, p<0.05]$. Bonferroni post hoc tests indicated that total object interactions decreased in epoch $2(p<0.05)$ and $3(p<0.01)$ compared to the first 5 min of the session; participants also exhibited less walking in epoch 3 relative to epoch $1(p<0.01)$. These data indicate an overall decrease in hBPM activity over time for all participants, regardless of group membership.

Given that multiple novel measures proposed in this paradigm are hypothesized to assess the one construct of inhibition, correlations between these measures were also quantified to assess their overlap and potential inter-item reliability (Table 3 ). The results indicated that all of the variables were consistently and significantly correlated with each other, with the singular exception of time spent in object-proximal sectors, a measure related only to the number of object-proximal sector entries. This finding may reflect the fact that some participants approach and visually examine novel objects from a close, proximal position, but do not always engage in physical contact (e.g., touching and manipulating the object). Overall, however, these data support the concept that the majority of the individual measures quantified in this study represent closely associated items with the potential to constitute a single psychometric scale to assess inhibitory deficits, in similar fashion to commonly

Table 3 Pearson $r$ correlations between the hBPM object interaction measures for all participants $(n=34)$

\begin{tabular}{|c|c|c|c|c|c|c|}
\hline & $\begin{array}{l}\text { Total number of } \\
\text { object interactions }\end{array}$ & $\begin{array}{l}\text { Mean time spent } \\
\text { with objects }\end{array}$ & $\begin{array}{l}\text { Percent } \\
\text { perseverative } \\
\text { interactions }\end{array}$ & $\begin{array}{l}\text { Time in object } \\
\text { proximal sectors }\end{array}$ & $\begin{array}{l}\text { Entries in object } \\
\text { proximal sectors }\end{array}$ & $\begin{array}{l}\text { Time spent } \\
\text { walking }\end{array}$ \\
\hline $\begin{array}{l}\text { Total number of } \\
\text { object interactions }\end{array}$ & - & $0.87 *$ & $0.75^{*}$ & 0.29 & $0.77 *$ & $0.63 *$ \\
\hline $\begin{array}{l}\text { Mean time spent } \\
\text { with objects }\end{array}$ & $0.87 *$ & - & $0.80 *$ & 0.27 & $0.72 *$ & $0.60 *$ \\
\hline $\begin{array}{l}\text { Percent } \\
\text { perseverative } \\
\text { interactions }\end{array}$ & $0.75^{*}$ & $0.80 *$ & - & -0.02 & $0.57 *$ & $0.53 * *$ \\
\hline $\begin{array}{l}\text { Time in object } \\
\text { proximal sectors }\end{array}$ & 0.29 & 0.27 & -0.02 & - & $0.47 * *$ & 0.18 \\
\hline $\begin{array}{l}\text { Entries in object } \\
\text { proximal sectors }\end{array}$ & $0.77 *$ & $0.72 *$ & $0.57 *$ & $0.47 * *$ & - & $0.83^{*}$ \\
\hline Time spent walking & $0.63 *$ & $0.60 *$ & $0.53 * *$ & 0.18 & $0.83 *$ & - \\
\hline
\end{tabular}

Multiple object interactions were not included here due to the low prevalence of this activity in our sample. All variables were significantly correlated with each other, with the exception of time spent in object proximal sectors

${ }^{*} p<0.001 ; * * p<0.01$, significant correlations 
used self-report scales of behavioral inhibition (Carver and White 1994).

We did not observe any significant correlation between hBPM measures and the length of MA use, the amount of total drug consumed, duration of abstinence, age of first use, or the frequency of monthly use. In contrast, the number of days of MA use in the past 12 months showed a trend towards a positive correlation with entries into object-proximal sectors $(r=0.43, p=$ $0.07)$, increased object perseveration $(r=0.43, p=0.07)$, and time spent walking $(r=0.45, p=0.06)$.

MA-dependent participants exhibited significant impairment on the WCST, including more total errors $[t(29)=3.4$, $p<0.01$ ], greater perseverative errors [ $t(29)=3.9, p<0.01]$, and fewer completed categories $[t(29)=3.2, p<0.01]$ compared to the drug-free comparison group. While none of the subjects finished all six WCST categories, the majority of drug-free participants $(80 \%)$, but only a small percentage of MA-dependent individuals (23\%), successfully completed five categories on the test. Total WCST errors were correlated with the mean time spent with objects, perseverative object interactions, and entries into object proximal sectors, indicating that poor performance on the WCST was associated with increased object interaction in the hBPM (Table 4). Interestingly, we also observed a strong trend towards a correlation between the WCST perseverative errors $T$ score and object perseveration $(r=-0.35, p=0.05)$ and mean time spent with objects $(r=$ $-0.39, p=0.03)$, indicating that perseveration on the WCST is likely associated with perseveration in the hBPM. Finally, the number of completed WCST categories was negatively correlated with the mean time spent with objects, object perseveration, and object-proximal sector entries (Table 4).

The MA-dependent group exhibited significantly higher total $(t(32)=-4.80, p<0.001)$ and positive symptom $(t(32)=-3.92, p<0.001)$ PANSS scores compared to drug-free comparison subjects (Table 1), but did not differ on the negative symptom scale $(t(32)=0.51, p=0.53)$. PANSS total and positive subscale scores were significantly correlated with total object interactions, time spent with objects, and percent perseverative interactions (Table 5).

\section{Discussion}

The findings of the current study indicate that abstinent MA-dependent individuals engaged in greater interaction with novel objects and demonstrated elevated perseverative behavior compared to drug-free comparison participants in a human open-field paradigm. While this is the first report to quantify inhibitory deficits associated with MA dependence in the context of a cross-species translational openfield test, our findings support a substantial literature demonstrating impaired inhibition characterized by inappropriate responses to stimuli and maladaptive perseveration in this population (Hoffman et al. 2006; Monterosso et al. 2005; Salo et al. 2009a; Salo et al. 2002; Salo et al. 2009b; Scott et al. 2007; Simon et al. 2000; Woods et al. 2005). Quantification of inhibitory deficits associated with MA use has considerable public health significance, since MA dependence is an established risk factor for hazardous sexual behavior, exposure to HIV and hepatitis C, and greater mortality associated with comorbid HIV infection (Bing et al. 2001; Galvan et al. 2002; Goodkin et al. 1998; Lucas et al. 2006; Nelson et al. 2002; Semple et al. 2006; Volkow et al. 2007). While drugs of abuse have been evaluated frequently in rodents and primates using objectoriented ambulatory tasks (Jentsch and Taylor 1999), behavioral deficits in human MA users have been measured primarily with neuropsychological paradigms with more limited real-world applicability (e.g., Stroop task). Use of

Table 4 Pearson $\mathrm{r}$ correlations between WCST scores and hBPM measures for all participants $(n=31)$

\begin{tabular}{lccc}
\hline Measure & \multicolumn{2}{l}{ WCST data } & \\
\cline { 2 - 4 } & Total errors $T$ score & Perseverative errors $T$ score & Categories completed \\
\hline Total number of object interactions & $-0.33^{\mathrm{a}}$ & $-0.31^{\mathrm{a}}$ & $-0.40^{\mathrm{a}}$ \\
Mean time spent with objects (seconds) & $-0.41^{*}$ & $-0.39^{\mathrm{a}}$ & $-0.45^{*}$ \\
Percent perseverative interactions & $-0.43^{*}$ & $-0.35^{\mathrm{a}}$ & $-0.53^{* *}$ \\
Time in object proximal sectors (seconds) & -0.16 & -0.18 & -0.12 \\
Entries in object proximal sectors & $-0.41^{*}$ & $-0.32^{\mathrm{a}}$ & $-0.42^{*}$ \\
Time spent walking (seconds) & -0.29 & -0.18 & $-0.33^{\mathrm{a}}$ \\
\end{tabular}

WCST total error and perseverative error data are calculated as $T$ scores normalized for age and gender. Greater object interaction, including more object perseveration, was associated with lower $T$ scores (indicating more WCST errors)

${ }^{*} p<0.025 ; * * p<0.01$, significant correlations

${ }^{\mathrm{a}}$ Indicates a trend $(p<0.1)$ 
Table 5 Pearson $r$ correlations between PANSS total and positive symptoms scores and hBPM measures for all participants $(n=34)$

\begin{tabular}{llll}
\hline Measure & \multicolumn{2}{l}{ PANSS } & \\
\cline { 2 - 4 } & $\begin{array}{l}\text { Total } \\
\text { score }\end{array}$ & $\begin{array}{l}\text { Positive } \\
\text { score }\end{array}$ & $\begin{array}{l}\text { Negative } \\
\text { score }\end{array}$ \\
\hline Total number of object interactions & $0.40^{*}$ & $0.45^{* *}$ & 0.01 \\
$\begin{array}{l}\text { Mean time spent with objects } \\
\quad \text { seconds) }\end{array}$ & $0.44^{* *}$ & $0.45^{* *}$ & 0.09 \\
$\begin{array}{llll}\text { Percent perseverative interactions } \\
\text { Time in object proximal sectors }\end{array}$ & $0.47^{*}$ & $0.48^{* *}$ & 0.09 \\
$\quad$ (seconds) & 0.25 & 0.22 & -0.08 \\
$\begin{array}{l}\text { Entries in object proximal sectors } \\
\text { Time spent walking (seconds) }\end{array}$ & $0.36^{\mathrm{a}}$ & $0.38^{\mathrm{a}}$ & -0.19 \\
\hline
\end{tabular}

Higher total and positive PANSS scores were associated with more total and perseverative object interactions and greater time spent with objects. No significant correlations were observed for the negative symptoms subscale

${ }^{*} p<0.025 ; * * p<0.01$, significant correlations

${ }^{\mathrm{a}}$ Indicates a trend $(p<0.1)$

an exploratory paradigm, such as the hBPM, allows us to quantify inhibition in a setting more germane to understanding the behavior of drug abusers (e.g., evaluating how an individual approaches and interacts with an engaging stimulus in the environment).

Several lines of evidence suggest that the behavioral responses of MA-dependent individuals in the hBPM may be mediated by inhibitory deficits associated with dysregulation of frontal cortex function. Frontal regions such as the PFC play a critical role in regulating the inhibition of motor and emotional responses by modulating activity in subcortical structures such as the striatum and amygdala (Dillon and Pizzagalli 2007; Jentsch and Taylor 1999). Our data indicate that poor WCST performance, a marker of impaired frontal function (Milner 1963), was correlated with greater object interaction in the hBPM, including a strong trend toward a relationship between perseverative errors on the WCST and perseverative object interactions $(p=0.05)$. In addition, a number of studies demonstrate that frontal cortex lesions also induce inappropriate or excessive object interaction activity (Diamond and Goldman-Rakic 1985; Lhermitte 1983; Moll and Kuypers 1977). For example, patients with frontal lobe lesions exhibit an increased tendency to grasp and manipulate objects they are presented in the absence of any instruction or communication from an examiner (Lhermitte 1983). Finally, both MA-dependent and manic BD subjects display a similar pattern of activity in the hBPM, characterized by greater object interaction and perseveration (Perry et al. 2010). Many studies report functional and structural PFC deficits associated with $\mathrm{BD}$ that are remarkably comparable to the effects of chronic MA exposure, including reductions in frontal gray matter density, cerebral blood flow, and metabolite levels (Drevets et al. 1997; Lyoo et al. 2004). These findings suggest that hBPM measures of exploratory behavior may reflect inhibitory deficits common to psychiatric illness and chronic drug exposure mediated by shared frontostriatal neuropathology.

Some groups have proposed that drug-seeking behavior is mediated by two primary factors, including both impaired inhibitory control and increased salience of the rewarding effects of the agent, described as the incentive sensitization theory of addiction (Jentsch and Taylor 1999; Robinson and Berridge 1993). Incentive sensitization, putatively meditated by neuroadaptations of the mesolimbic dopamine system (Jentsch and Taylor 1999), involves an increase in the attractiveness or degree of "wanting" associated with repeated exposure to a positive stimulus. While we contend that behavioral responses in the hBPM are driven by impaired inhibitory processes, as supported by neurobiological and neuropsychological findings, the current data does not exclude the possibility that responses to novel objects may be impacted by alterations in their perceived salience in MA-dependent individuals. It is relevant to note that the hBPM paradigm does differ from typical sensitization paradigms in that the novel stimuli are presented only once and they are "neutral" in nature (e.g., not involving or associated with drug administration). Future studies might address this issue more directly by assessing responses to specific MA-associated objects (e.g., drug-specific paraphernalia) that could be placed in the room.

MA-dependent participants in this study did exhibit quite low, but significantly higher total and positive symptom PANSS scores compared to drug-free participants. However, the average total PANSS score in the MA-dependent group was approximately 44, well below the ranges designated as moderate or even mild illness (e.g., above 60) (Leucht et al. 2005). PANSS scores were positively correlated with increased object interaction, suggesting that alterations in inhibition could be related to the emergence of drug-related abnormal perceptions or thoughts, even if such symptoms are not severe enough to merit a diagnosis of MA-induced psychosis.

The current findings do have a number of limitations that warrant discussion. The sample size was relatively small, so additional studies assessing hBPM activity in larger populations would be appropriate to determine if the data are representative of adults with a history of MA dependence. In addition, the MA-dependent group included a greater number of smokers, although the difference between the two groups did not reach significance. Recent studies demonstrate that nicotine exposure and withdrawal may impact inhibitory functioning on measures such as prepulse inhibition and the continuous performance task (Harrison et al. 2009; Rabin et al. 2009); thus, we cannot exclude the 
possibility that nicotine use may affect measures in our paradigm. As with many studies that examine the effect of drug use on behavior, it is possible that preexisting conditions may influence our measures. For example, premorbid deficits in executive function or inhibition may increase the probability of engaging in MA use, mediated by PFC abnormalities predating drug exposure. While more frequent MA use in the past year showed a weak association with increased exploration, hBPM activity was not related to other parameters of drug use. These results are not unique, as many other studies have observed a lack of correspondence between MA use parameters and MArelated neuropsychological impairment (Chang et al. 2002; Cherner et al. 2010; Johanson et al. 2006; McCann et al. 1998); such findings may reflect poor self-report or individual variation in vulnerability to MA-induced neurocognitive injury (Cherner et al. 2010). Finally, recent data have suggested that deficits associated with MA exposure may normalize following extended (over 1 year) periods of abstinence (Iudicello et al. 2010). Given that the average length of abstinence in the current sample was 9-10 months, the group differences we observed may diminish after more extended recovery from the drug.

In conclusion, a sample of abstinent MA-dependent individuals exhibited increased interaction with novel stimuli and elevated perseverative responses compared to a drug-free comparison group in a novel open-field paradigm. Utilization of cross-species translational measures such as the hBPM may facilitate more comprehensive assessment of inhibitory deficits associated with drug use, improve validation of concurrent animal models (Young et al. 2010), and enable the development of treatment and intervention methods in substance abuse populations.

Acknowledgements The manuscript was supported by National Research Service Award F32DA024524-02, the Translational Methamphetamine AIDS Research Center (TMARC) (5P50DA026306) funded by the National Institute On Drug Abuse (NIDA), and a grant from the National Institute of Mental Health (NIMH) (R01MH071916). Additional support was provided by the HIV Neurobehavioral Research Center CSPAR Developmental Grant Award (\# HNRC-819). The content is solely the responsibility of the authors and does not necessarily represent the official views of NIDA or NIMH. The authors gratefully thank Rodney von Jaeger and Terence Hendrix for their contribution in recruiting participants involved in this study.

The TMARC group is affiliated with the University of California, San Diego; the Naval Hospital, San Diego; and the Veterans Affairs San Diego Healthcare System and includes director Igor Grant, M.D.; co-directors: Scott Letendre, M.D.; Ronald J. Ellis, M.D., Ph.D.; and Christian Achim, M.D., Ph.D.; center manager: Steven Woods, Psy. D.; Sara Ortiz, B.A.; Melanie Sherman; Naval Hospital San Diego; Clinical Assessment and Laboratory Core: Scott Letendre, M.D. (P.I.); Ronald J. Ellis, M.D., Ph.D.; Rachel Schrier, Ph.D.; Will Toperoff, R. N., F.N.P.; Alana Talob, Michael Potter; Edmund Capparelli, Pharm. D., Jennifer Marquie-Beck, Terry Alexander, R.N.; neuropsychiatric core: Robert Heaton, Ph.D. (P.I.); J. Hampton Atkinson, M.D.;
Mariana Cherner, Ph.D.; Thomas Marcotte, Ph.D.; Nichole Duarte, M.S.; Mili Parikh, Rachel Meyer B.A.; Adam Aron, Ph.D.; Matthew Dawson; neuroimaging core: Gregory Brown, Ph.D. (P.I.); Sarah Archibald, M.A.; Anders Dale, Ph.D.; C. Fenema-Notestine, Ph.D.; Terry Jernigan, Ph.D.; Thomas Liu, Ph.D.; Miriam Scadeng, Ph.D.; Brad Beyenhof, and Dexter Walpole; neuroscience and animal models core: Christian Achim, M.D., Ph.D. (P.I.); Eliezer Masliah, M.D.; Ian Everall, M.D., Ph.D.; Stuart Lipton, M.D.; Ph.D.; Virawudh Soontornniyomkij, M.D.; Erick Tatro, Ph.D.; Amir Sabouri, M.D., Ph.D.; Michael Mante; Dongxian Zhang, Ph.D.; project 1: Arpi Minassian, Ph.D. (P.I.); William Perry, Ph.D.; Mark Geyer, Ph.D.; Brook Henry, Ph.D.; Mahalah Buell; project 2: Amanda Grethe, Ph.D. (P.I.); Martin Paulus, M.D.; Ronald Ellis, M.D., Ph.D.; project 3: Sheldon Morris, M.D., M.P.H. (P.I.); David Smith, M.D., M.A.S.; Igor Grant, M.D.; DeeDee Pacheco; project 4: Svetlana Semenova, Ph.D. (P.I.); Athina Markou, Ph.D.; project 5: Marcus Kaul, Ph.D. (P.I.); participant unit: J. Hampton Atkinson, M.D. (P.I.); Rodney von Jaeger, M.P.H.; Teresa Oyos; Terence Hendrix; Richard Seghers; data management unit: Anthony C. Gamst, Ph.D. (P.I.); Clint Cushman, B.A. (data systems manager); Michael Repinski; Jose Mendez; and statistics unit: Ian Abramson, Ph.D. (P.I.); Christopher Ake, Ph.D.; Reena Deutsch, Ph. D.; Florin Vaida, Ph.D.

Conflicts of interest We hereby declare we have no conflicts with this research and did not receive funds from a commercial sponsor.

Open Access This article is distributed under the terms of the Creative Commons Attribution Noncommercial License which permits any noncommercial use, distribution, and reproduction in any medium, provided the original author(s) and source are credited.

\section{References}

Barr AM, Panenka WJ, MacEwan GW, Thornton AE, Lang DJ, Honer WG, Lecomte T (2006) The need for speed: an update on methamphetamine addiction. J Psychiatry Neurosci 31:301-313

Bing EG, Burnam MA, Longshore D, Fleishman JA, Sherbourne CD, London AS, Turner BJ, Eggan F, Beckman R, Vitiello B, Morton SC, Orlando M, Bozzette SA, Ortiz-Barron L, Shapiro M (2001) Psychiatric disorders and drug use among human immunodeficiency virus-infected adults in the United States. Arch Gen Psychiatry 58:721-728

Carver CS, White TL (1994) Behavioral inhibition, behavioral activation, and affective responses to impending reward and punishment: the BIS/BAS Scales. J Pers Soc Psychol 67:319-333

Chang L, Ernst T, Speck O, Patel H, DeSilva M, Leonido-Yee M, Miller EN (2002) Perfusion MRI and computerized cognitive test abnormalities in abstinent methamphetamine users. Psychiatry Res 114:65-79

Cherner M, Suarez P, Casey C, Deiss R, Letendre S, Marcotte T, Vaida F, Atkinson JH, Grant I, Heaton RK (2010) Methamphetamine use parameters do not predict neuropsychological impairment in currently abstinent dependent adults. Drug Alcohol Depend 106:154-163

Chung A, Lyoo IK, Kim SJ, Hwang J, Bae SC, Sung YH, Sim ME, Song IC, Kim J, Chang KH, Renshaw PF (2007) Decreased frontal white-matter integrity in abstinent methamphetamine abusers. Int J Neuropsychopharmacol 10:765-775

Diamond A, Goldman-Rakic PS (1985) Evidence for the involvement of prefrontal cortex in cognitive changes during the first year of life: comparison of performance of human infants and rhesus monkeys on a detour task with a transparent barrier. Soc Neurosci Abstr 11:832 
Dias R, Robbins TW, Roberts AC (1996) Primate analogue of the Wisconsin Card Sorting Test: effects of excitotoxic lesions of the prefrontal cortex in the marmoset. Behav Neurosci 110:872-886

Dillon DG, Pizzagalli DA (2007) Inhibition of action, thought, and emotion: a selective neurobiological review. Appl Prev Psychol 12:99-114

Drevets WC, Price JL, Simpson JR Jr, Todd RD, Reich T, Vannier M, Raichle ME (1997) Subgenual prefrontal cortex abnormalities in mood disorders. Nature 386:824-827

Dunn LM, Dunn LM (1997) Peabody picture vocabulary test (3rd ed.). Pearson Assessment Group, Circle Pines

Ellison GD, Eison MS (1983) Continuous amphetamine intoxication: an animal model of the acute psychotic episode. Psychol Med 13:751-761

File SE, Wardill AG (1975) Validity of head-dipping as a measure of exploration in a modified hole-board. Psychopharmacologia 44:53-59

First MB, Spitzer RL, Gibbon M, Williams JBW (1994) Structured clinical interview for axis I DSM-IV disorders (SCID). Psychiatric Press, Washington

Galvan FH, Bing EG, Fleishman JA, London AS, Caetano R, Burnam MA, Longshore D, Morton SC, Orlando M, Shapiro M (2002) The prevalence of alcohol consumption and heavy drinking among people with HIV in the United States: results from the HIV cost and services utilization study. J Stud Alcohol 63:179186

Geyer MA, Russo PV, Masten VL (1986) Multivariate assessment of locomotor behavior: pharmacological and behavioral analyses. Pharmacol Biochem Behav 25:277-288

Goldberg JO, Miller HR (1986) Performance of psychiatric inpatients and intellectually deficient individuals on a task that assesses the validity of memory complaints. J Clin Psychol 42:792-795

Goodkin K, Shapshak P, Metsch LR, McCoy CB, Crandall KA, Kumar M, Fujimura RK, McCoy V, Zhang BT, Reyblat S, Xin KQ, Kumar AM (1998) Cocaine abuse and HIV-1 infection: epidemiology and neuropathogenesis. J Neuroimmunol 83:88101

Goodwin F, Jamison K (1990) Manic-depressive illness. Oxford University Press, New York

Harrison EL, Coppola S, McKee SA (2009) Nicotine deprivation and trait impulsivity affect smokers' performance on cognitive tasks of inhibition and attention. Exp Clin Psychopharmacol 17:91-98

Heaton RK (1993) WCST: Computer version-2 research edition manual. Psychological Assessment Resources, Odessa

Henry BL, Minassian A, Paulus MP, Geyer MA, Perry W (2009) Heart rate variability in bipolar mania and schizophrenia. J Psychiatr Res 44:168-176

Henry BL, Minassian A, Perry W (2010) Effect of methamphetamine dependence on everyday functional ability. Addictive Behaviors 35:593-598

Hoffman WF, Moore M, Templin R, McFarland B, Hitzemann RJ, Mitchell SH (2006) Neuropsychological function and delay discounting in methamphetamine-dependent individuals. Psychopharmacology (Berl) 188:162-170

Iudicello JE, Woods SP, Vigil O, Cobb Scott J, Cherner M, Heaton RK, Hampton Atkinson J, Grant I (2010) Longer term improvement in neurocognitive functioning and affective distress among methamphetamine users who achieve stable abstinence. J Clin Exp Neuropsychol 32(7):704-718, 1-18

Jentsch JD, Taylor JR (1999) Impulsivity resulting from frontostriatal dysfunction in drug abuse: implications for the control of behavior by reward-related stimuli. Psychopharmacology (Berl) 146:373-390

Johanson CE, Frey KA, Lundahl LH, Keenan P, Lockhart N, Roll J, Galloway GP, Koeppe RA, Kilbourn MR, Robbins T, Schuster CR (2006) Cognitive function and nigrostriatal markers in abstinent methamphetamine abusers. Psychopharmacology (Berl) (in press)

Kalechstein AD, Newton TF, Green M (2003) Methamphetamine dependence is associated with neurocognitive impairment in the initial phases of abstinence. J Neuropsychiatry Clin Neurosci 15:215-220

Kim SJ, Lyoo IK, Hwang J, Sung YH, Lee HY, Lee DS, Jeong DU, Renshaw PF (2005) Frontal glucose hypometabolism in abstinent methamphetamine users. Neuropsychopharmacology 30:1383-1391

Kim SJ, Lyoo IK, Hwang J, Chung A, Hoon Sung Y, Kim J, Kwon DH, Chang KH, Renshaw PF (2006) Prefrontal grey-matter changes in short-term and long-term abstinent methamphetamine abusers. Int J Neuropsychopharmacol 9:221-228

Leibenluft E, Rich BA, Vinton DT, Nelson EE, Fromm SJ, Berghorst LH, Joshi P, Robb A, Schachar RJ, Dickstein DP, McClure EB, Pine DS (2007) Neural circuitry engaged during unsuccessful motor inhibition in pediatric bipolar disorder. Am J Psychiatry 164:52-60

Leucht S, Kane JM, Kissling W, Hamann J, Etschel E, Engel RR (2005) What does the PANSS mean? Schizophr Res 79:231-238

Lhermitte F (1983) 'Utilization behaviour' and its relation to lesions of the frontal lobes. Brain 106(Pt 2):237-255

Lucas GM, Griswold M, Gebo KA, Keruly J, Chaisson RE, Moore RD (2006) Illicit drug use and HIV-1 disease progression: a longitudinal study in the era of highly active antiretroviral therapy. Am J Epidemiol 163:412-420

Lyoo IK, Kim MJ, Stoll AL, Demopulos CM, Parow AM, Dager SR, Friedman SD, Dunner DL, Renshaw PF (2004) Frontal lobe gray matter density decreases in bipolar I disorder. Biol Psychiatry 55:648-651

McCann UD, Wong DF, Yokoi F, Villemagne V, Dannals RF, Ricaurte GA (1998) Reduced striatal dopamine transporter density in abstinent methamphetamine and methcathinone users: evidence from positron emission tomography studies with [11C]WIN-35, 428. J Neurosci 18:8417-8422

McKetin R, McLaren J, Lubman DI, Hides L (2006) The prevalence of psychotic symptoms among methamphetamine users. Addiction 101:1473-1478

Milner B (1963) Effects of different brain lesions on card sorting: the role of the frontal lobes. Arch Neurol 9:90-100

Minassian A, Henry BL, Geyer MA, Paulus MP, Young JW, Perry W (2009) The quantitative assessment of motor activity in mania and schizophrenia. J Affect Disord 120:200-206

Moll L, Kuypers HG (1977) Premotor cortical ablations in monkeys: contralateral changes in visually guided reaching behavior. Science 198:317-319

Monterosso JR, Aron AR, Cordova X, Xu J, London ED (2005) Deficits in response inhibition associated with chronic methamphetamine abuse. Drug Alcohol Depend 79:273-277

Nelson KE, Galai N, Safaeian M, Strathdee SA, Celentano DD, Vlahov D (2002) Temporal trends in the incidence of human immunodeficiency virus infection and risk behavior among injection drug users in Baltimore, Maryland, 1988-1998. Am J Epidemiol 156:641-653

Opler MG, Yang LH, Caleo S, Alberti P (2007) Statistical validation of the criteria for symptom remission in schizophrenia: preliminary findings. BMC Psychiatry 7:35

Perry W, Braff DL (1998) A multimethod approach to assessing perseverations in schizophrenia patients. Schizophr Res 33:69-77

Perry W, Minassian A, Paulus MP, Young JW, Kincaid MJ, Ferguson EJ, Henry BL, Zhuang X, Masten VL, Sharp RF, Geyer MA (2009) A reverse-translational study of dysfunctional exploration in psychiatric disorders: from mice to men. Arch Gen Psychiatry 66:1072-1080

Perry W, Minassian A, Henry B, Kincaid M, Young JW, Geyer MA (2010) Quantifying over-activity in bipolar and schizophrenia 
patients in a human open field paradigm. Psychiatry Res 178:8491

Pierce K, Courchesne E (2001) Evidence for a cerebellar role in reduced exploration and stereotyped behavior in autism. Biol Psychiatry 49:655-664

Rabin RA, Sacco KA, George TP (2009) Correlation of prepulse inhibition and Wisconsin card sorting test in schizophrenia and controls: effects of smoking status. Schizophr Res 114:91-97

Rippeth JD, Heaton RK, Carey CL, Marcotte TD, Moore DJ, Gonzalez R, Wolfson T, Grant I (2004) Methamphetamine dependence increases risk of neuropsychological impairment in HIV infected persons. J Int Neuropsychol Soc 10:1-14

Robinson TE, Berridge KC (1993) The neural basis of drug craving: an incentive-sensitization theory of addiction. Brain Res Brain Res Rev 18:247-291

Romanelli F, Smith KM (2006) Clinical effects and management of methamphetamine abuse. Pharmacotherapy 26:1148-1156

Rosenthal R (1991) Meta-analysis: a review. Psychosom Med 53:247271

Sakagami M, Pan X, Uttl B (2006) Behavioral inhibition and prefrontal cortex in decision-making. Neural Netw 19:12551265

Salo R, Nordahl TE, Possin K, Leamon M, Gibson DR, Galloway GP, Flynn NM, Henik A, Pfefferbaum A, Sullivan EV (2002) Preliminary evidence of reduced cognitive inhibition in methamphetaminedependent individuals. Psychiatry Res 111:65-74

Salo R, Nordahl TE, Galloway GP, Moore CD, Waters C, Leamon MH (2009a) Drug abstinence and cognitive control in methamphetamine-dependent individuals. J Subst Abuse Treat 37:292-297

Salo R, Ursu S, Buonocore MH, Leamon MH, Carter C (2009b) Impaired prefrontal cortical function and disrupted adaptive cognitive control in methamphetamine abusers: a functional magnetic resonance imaging study. Biol Psychiatry 65:706709

Scott JC, Woods SP, Matt GE, Meyer RA, Heaton RK, Atkinson JH, Grant I (2007) Neurocognitive effects of methamphetamine: a critical review and meta-analysis. Neuropsychol Rev $17: 275-297$
Semple SJ, Zians J, Grant I, Patterson TL (2006) Sexual compulsivity in a sample of HIV-positive methamphetamine-using gay and bisexual men. AIDS Behav 10:587-598

Semple SJ, Strathdee SA, Zians J, Patterson TL (2010) Factors associated with sex in the context of methamphetamine use in different sexual venues among HIV-positive men who have sex with men. BMC Public Health 10:178

Simon SL, Domier C, Carnell J, Brethen P, Rawson R, Ling W (2000) Cognitive impairment in individuals currently using methamphetamine. Am J Addict 9:222-231

Simon SL, Domier CP, Sim T, Richardson K, Rawson RA, Ling W (2002) Cognitive performance of current methamphetamine and cocaine abusers. J Addict Dis 21:61-74

Substance Abuse and Mental Health Services Administration (2009) The TEDS Report: Trends in Methamphetamine Admissions to Treatment: 1997-2007. Rockville, MD

U.S. Department of Justice National Drug Intelligence Center (2010) National Drug Threat Assessment. Washington, D.C.

Vivometrics (2002) The LifeShirt system ${ }^{\mathrm{TM}}$. Ventura, CA

Volkow ND, Wang GJ, Fowler JS, Telang F, Jayne M, Wong C (2007) Stimulant-induced enhanced sexual desire as a potential contributing factor in HIV transmission. Am J Psychiatry 164:157-160

Watanabe-Galloway S, Ryan S, Hansen K, Hullsiek B, Muli V, Malone AC (2009) Effects of methamphetamine abuse beyond individual users. J Psychoactive Drugs 41:241-248

Woods SP, Rippeth JD, Conover E, Gongvatana A, Gonzalez R, Carey CL, Cherner M, Heaton RK, Grant I (2005) Deficient strategic control of verbal encoding and retrieval in individuals with methamphetamine dependence. Neuropsychology 19:35-43

Young JW, Minassian A, Paulus MP, Geyer MA, Perry W (2007) A reverse-translational approach to bipolar disorder: rodent and human studies in the behavioral pattern monitor. Neurosci Biobehav Rev 31:882-896

Young JW, Goey AK, Minassian A, Perry W, Paulus MP, Geyer MA (2010) GBR 12909 administration as a mouse model of bipolar disorder mania: mimicking quantitative assessment of manic behavior. Psychopharmacology (Berl) 208:443-454

Zar JH (1999) Biostatistical analysis, 4th edn. Prentice Hall, Upper Saddle River 